\title{
Comparison of intravenous dexmedetomidine and intravenous fentanyl to attenuate the hemodynamic stress response to tracheal extubation
}

\author{
R. Amutharani ${ }^{1}$, T. Manoharan ${ }^{2 *}$, P. Manickavasagam ${ }^{3}$, Heber Anandan ${ }^{4}$ \\ ${ }^{1}$ Professor and Head, ${ }^{2}$ Senior Assistant Professor, ${ }^{3} \mathrm{PG}$ Student, ${ }^{4}$ Clinical Epidemiologist, ${ }^{1-3}$ Dept. of Anesthesiology, ${ }^{4}$ Dept. of Clinical \\ Research, ${ }^{1-3}$ Tirunelveli Medical College Hospital, Tamil Nadu, ${ }^{4}$ Dr. Agarwal's Healthcare Limited, India
}

*Corresponding Author: T. Manoharan

Email: manoharans90@gmail.com

Received: $15^{\text {th }}$ February, 2019

Accepted: $8^{\text {th }}$ March, 2019

\begin{abstract}
Introduction: Endotracheal extubation can be associated with hypertension, tachycardia, arrhythmias, myocardial ischemia and raised intracranial pressures due to sympathetic stimulation.

Aim: To compare the efficacy of dexmedetomidine, fentanyl and placebo in decreasing stress response to tracheal extubation in elective general surgery patients.

Materials and Methods: 180 patients of either sex, ASA grade I -II normotensive, aged 18-65 years undergoing elective general surgeries of 60-180 minutes duration under general anaesthesia were randomized into 3 groups. Anaesthetic technique was standardized. Patients in Group N, F and D received an IV infusion of $100 \mathrm{ml}$ of $0.9 \%$ normal saline, fentanyl $1 \mu \mathrm{g} / \mathrm{kg}$ and dexmedetomidine $0.5 \mu \mathrm{g} / \mathrm{kg}$ respectively 10 minutes before extubation for a period of 10 minutes. HR, SBP, DBP, MAP and $\mathrm{SPO}_{2}$ were recorded before, during and after extubation.

Results: Statistically significant lesser increase in HR, SBP, DBP, MAP were noted after extubation in the dexmedetomidine group than the fentanyl group. Dexmedetomidine group had better extubation quality than the fentanyl group. Ramsay sedation and Aldrete scores were similar in all 3 groups. Hypotension and bradycardia were more with dexmedetomidine group than the fentanyl group but none required intervention.

Conclusion: Dexmedetomidine $0.5 \mu \mathrm{g} / \mathrm{kg}$ infusion administered 10 minutes before tracheal extubation was better compared to fentanyl $1 \mu \mathrm{g} / \mathrm{kg}$ infusion in attenuating the hemodynamic stress response with comparable adverse effects. Hence, dexmedetomidine infusion can be a safer alternative to fentanyl infusion for attenuating extubation stress response.
\end{abstract}

Keywords: Dexmedetomidine, Fentanyl, Extubation, Hemodynamic response.

\section{Introduction}

Endotracheal extubation is the translaryngeal removal of a tube from trachea via nose or mouth. Complications during and after extubation are more common than during tracheal intubation and induction of anaesthesia. Hypertension and tachycardia are common events during extubation. Arrhythmias, myocardial ischemia, raised intracranial and intraocular pressures can occur. ${ }^{1}$ There should be the absence of coughing, straining, laryngospasm, bronchospasm and breath holding for smooth extubation. ${ }^{2}$ Drugs that have been recommended for the control of these hemodynamic events including opioids, lignocaine, beta blockers, calcium channel blockers and alpha 2 agonists. ${ }^{3,4}$ Dexmedetomidine is the highly selective alpha 2-receptor agonist which has sympatholytic, anxiolytic, sedative and analgesic properties. It reduces the cardiovascular responses in the perioperative period. ${ }^{5}$ Fentanyl is an opioid that attenuates hemodynamic response to extubation. It also decreases the airway reflexes to extubation and does not prolong the recovery time. ${ }^{3}$ It is found that an infusion of dexmedetomidine $1 \mu \mathrm{g} / \mathrm{kg}$ is better than fentanyl infusion of $1 \mu \mathrm{g} / \mathrm{kg}$ before extubation to decrease the hemodynamic surge during extubation. Dexmedetomidine $1 \mu \mathrm{g} / \mathrm{kg}$ infusion has a higher sedation score compared to fentanyl $1 \mu \mathrm{g} / \mathrm{kg}$ infusion. ${ }^{6}$ Attenuation of stress response to extubation by dexmedetomidine $0.5 \mu \mathrm{g} / \mathrm{kg}$ infusion is as effective as dexmedetomidine $1 \mu \mathrm{g} / \mathrm{kg}$ infusion, ${ }^{7}$ hence in my study I have compared $0.5 \mu \mathrm{g} / \mathrm{kg}$ of dexmedetomidine infusion with $1 \mu \mathrm{g} / \mathrm{kg}$ of fentanyl infusion to reduce the sedation score and adverse events associated with $1 \mu \mathrm{g} / \mathrm{kg}$ of dexmedetomidine infusion.

\section{Aim}

To compare the efficacy of dexmedetomidine, fentanyl and placebo in decreasing stress response to tracheal extubation in elective general surgery patients

\section{Materials and Methods}

A prospective, double-blinded, randomized controlled study was conducted in the Department of Anaesthesiology, Tirunelveli Medical College Hospital in patients posted for elective general surgeries under general anaesthesia from January 2018 to August 2018. Randomization done with sealed enveloped technique.

\section{Inclusion Criteria}

ASA (American Society of Anaesthesiologist) grade I and II of either sex, age 18 to 65 years, scheduled under general anaesthesia for elective general surgeries, duration of surgery- 60 to 180 minutes.

\section{Exclusion Criteria}

Patients who are or with allergic to dexmedetomidine or fentanyl, cardiovascular disorder, respiratory disorder, diabetes, hypertension, obesity $(\mathrm{BMI}=$ or $>30 \mathrm{~kg} / \mathrm{m} 2)$, difficult airway (Modified Mallampati Grade III and IV), medications that affect HR or blood pressure, pregnant, 
history of sleep apneoa, hepatic impairment, renal impairment.

Using sealed enveloped technique patients were categorized into 3 different groups.

Group N: (n=60) $100 \mathrm{ml}$ of normal saline

Group F: $(\mathrm{n}=60)$ fentanyl $(1 \mu \mathrm{g} / \mathrm{kg})$ in $100 \mathrm{ml}$ of normal saline Group D: $(\mathrm{n}=60)$ dexmedetomidine $(0.5 \mu \mathrm{g} / \mathrm{kg})$ in $100 \mathrm{ml}$ of normal saline.

All the patients were kept nil oral 8 hours before surgery. Patients were given Inj. Glycopyrrolate $10 \mu \mathrm{g} / \mathrm{kg}$ iv, Inj. Midazolam $40 \mu \mathrm{g} / \mathrm{kg}$ iv, Inj. Ondansetron $100 \mu \mathrm{g} / \mathrm{kg}$ iv, Inj. Ranitidine $1 \mathrm{mg} / \mathrm{kg}$ iv as premedication. Three lead electrocardiogram, non-invasive blood pressure, pulse oximeter and capnograph were attached for monitoring. $100 \%$ oxygen for 3 minutes was given as pre-oxygenation. Induction of the patient is done with Inj. Fentanyl $2 \mu \mathrm{g} / \mathrm{kg}$ iv, Inj. Thiopentone sodium $5 \mathrm{mg} / \mathrm{kg}$ iv, Inj. Atracurium 0.5 $\mathrm{mg} / \mathrm{kg}$ iv and intubation were done with a suitable endotracheal tube. Oxygen and nitrous oxide were used in the ratio of 40:60 for the maintenance of anaesthesia along with isoflurane 0.8 to $1.5 \%$. Inj. Atracurium $0.125 \mathrm{mg} / \mathrm{kg}$ iv was repeated at intervals with capnograph monitoring for the maintenance of muscle relaxation. Volume replacement and maintenance were done with ringer lactate and DNS. Isoflurane was cut off 10 minutes before anticipated extubation time in all the 3 groups. Test drugs were prepared by the persons not involved in the study and were handed over to the anaesthetists, who were unaware of the drugs. Group $\mathrm{N}$ patients received $100 \mathrm{ml}$ of normal saline, Group $\mathrm{F}$ patients received $1 \mu \mathrm{g} / \mathrm{kg}$ of fentanyl in $100 \mathrm{ml}$ of normal saline and Group D received $0.5 \mu \mathrm{g} / \mathrm{kg}$ of dexmedetomidine in $100 \mathrm{ml}$ of normal saline over a period of 10 minutes before the anticipated extubation time. Patients were reversed with
Inj. Neostigmine $50 \mu \mathrm{g} / \mathrm{kg}$ iv and Inj.Glycopyrrolate $10 \mu \mathrm{g} / \mathrm{kg}$ iv after adequate spontaneous breathing efforts. Baseline hemodynamic parameters like HR and systolic, diastolic and mean arterial blood pressures were recorded. Baseline saturation is also recorded. All the above parameters were recorded after induction and intubation, 10 minutes before extubation, 5 minutes before extubation, during extubation and at 2, 4,6,8,10,25,40,55,70,85,100,115,130 minutes after extubation.

Quality of extubation was evaluated based on cough immediately after extubation, using a five- point rating scale (extubation quality score):

1. No coughing

2. Smooth extubation, minimal coughing ( 1 or 2 times)

3. Moderate coughing ( 3 or 4 times)

4. Severe coughing (5-10 times) and straining

5. Poor extubation, very uncomfortable (laryngospasm and coughing $>10$ times).

Postoperative sedation was assessed on a six-point scale (Ramsay scale).

1. Anxious or agitated and restless or both

2. Cooperative, oriented and tranquilized.

3. Drowsy but responds to commands.

4. Asleep, brisk response to light glabellar tap or loud auditory stimulus.

5. Asleep, sluggish response to light glabellar tap or loud auditory stimulus.

6. Asleep and unarousable.

Aldrete scoring was also recorded at 25 minutes following extubation before sending the patients from the recovery room to the wards.

\begin{tabular}{|c|c|c|}
\hline Parameters & Description of the patient & Score \\
\hline \multirow{3}{*}{ Activity level } & Moves all extremities voluntarily/on command & 2 \\
\hline & Moves 2 extremities & 1 \\
\hline & Cannot move extremities & 0 \\
\hline \multirow{3}{*}{ Respiration } & Breathes deeply and coughs freely & 2 \\
\hline & Is dyspneic, with shallow, limited breathing & 1 \\
\hline & Is apneic & 0 \\
\hline \multirow{3}{*}{ Circulation (blood pressure) } & Is $20 \mathrm{mmHg}>$ preanesthetic level & 2 \\
\hline & Is 20 to $50 \mathrm{mmHg}>$ preanesthetic level & 1 \\
\hline & Is $50 \mathrm{mmHg}>$ preanesthetic level & 0 \\
\hline \multirow{3}{*}{ Consciousness } & Is fully awake & 2 \\
\hline & Is arousable on calling & 1 \\
\hline & Is not responding & 0 \\
\hline \multirow{3}{*}{$\begin{array}{l}\text { Oxygen saturation as determined } \\
\text { by pulse oximetry }\end{array}$} & Has level $>90 \%$ when breathing room air & 2 \\
\hline & Requires supplemental oxygen to maintain level $>90 \%$ & 1 \\
\hline & Has level $<90 \%$ with oxygen supplementation & 0 \\
\hline
\end{tabular}

Maximum total score is 10 ; a score of $\geq 9$ is required for discharge. 
One way ANOVA test is used for Continuous variables like

1. Age

2. Surgery duration

3. Body Mass Index

4. Heart rate

5. Systolic Blood Pressure

6. Diastolic Blood Pressure

7. Mean Arterial Pressure.

Pearson's Chi-squared test is used for Categorical variables like

1. ASA Physical Status

2. Gender

3. Extubation Quality Score

4. Ramsay Sedation Score

5. Bradycardia

6. Hypotension

7. Vomiting.

Statistical analysis is made with IBM SPSS 16.0 software and a $P$ value of $<0.05$ is considered significant.

\section{Sample Size Calculation}

Calculated using the following formula based on the earlier study by Liyakath et $\mathrm{al}^{6}$ comparing effects of dexmedetomidine $(1 \mu \mathrm{g} / \mathrm{kg})$ with fentanyl $(1 \mu \mathrm{g} / \mathrm{kg})$ and considering systolic blood pressure as a variable. In their study, maximum systolic blood pressure in the fentanyl group and dexmedetomidine group were found to be $136 \pm 13 \mathrm{mmHg}$ and $130 \pm 9 \mathrm{mmHg}$. Applying $\mu 1=136$ and $\mu 2=130, \mathrm{n}$ is calculated as 55 .

\section{To test the difference of two means}

$$
\begin{aligned}
& \mathrm{n}=\frac{\mathrm{Z}(\alpha+\mathrm{Z} \beta)^{2} * \sigma^{2} * 2}{(\mu 1-\mu 2)^{2}} \\
& \sigma^{2}=\frac{\mathrm{s} 1^{2}(\mathrm{n} 1-1)+\mathrm{s} 2^{2}(\mathrm{n} 2-1)}{\mathrm{n} 1+\mathrm{n} 2-2} \\
& \mathrm{n}=\text { sample size } \\
& \sigma^{2}=\text { pooled variance } \\
& \mathrm{Z} \alpha=\text { at } 95 \% \mathrm{CI}+1.96
\end{aligned}
$$

$$
\begin{aligned}
& \mathrm{s}=\text { standard deviation } \\
& \mu=\text { mean }
\end{aligned}
$$

Considering $10 \%$ compensation for "drop out" or "loss of follow up" sample size is taken as 60 for each groups.

\section{Results}

One hundred and eighty patients were allocated into 3 groups of 60 each -group $\mathrm{N}$ received $100 \mathrm{ml}$ of normal saline, group $\mathrm{F}$ received $1 \mu \mathrm{g} / \mathrm{kg}$ of fentanyl in $100 \mathrm{ml}$ of normal saline, group D received $0.5 \mu \mathrm{g} / \mathrm{kg}$ of dexmedetomidine in $100 \mathrm{ml}$ of normal saline. Mean age of the study patients was $39.13 \pm 10.86$ years, 101 female patients, 79 male patients, and there is no difference in demographic data, ASA and duration of surgery of the study group. Dexmedetomidine group had a statistically significant lesser increase in HR than the fentanyl group during extubation and up to 100 minutes after extubation. Dexmedetomidine group had statistically significant control of SBP than the fentanyl group during extubation and upto 70 minutes after extubation. Dexmedetomidine group showed a lesser rise in DBP and mean arterial pressure compared to fentanyl group from 5 minutes before extubation to 130 minutes after extubation which was statistically significant. Dexmedetomidine group had a better quality of extubation compared to the fentanyl group. Ramsay sedation score in the initial 25 minutes of the post-operative period was statistically insignificant between the dexmedetomidine and fentanyl groups. When compared to fentanyl group bradycardia was found to be more with the dexmedetomidine group but none required intervention. Dexmedetomidine group had less vomiting compared to the fentanyl group and found to be statistically insignificant. Dexmedetomidine group had hypotension in more patients compared to fentanyl group which had no hypotension and also found to be statistically insignificant. Adverse effects like respiratory depression, laryngospasm, bronchospasm or desaturation were not observed in both the groups. Recovery profile is similar in dexmedetomidine and fentanyl group.

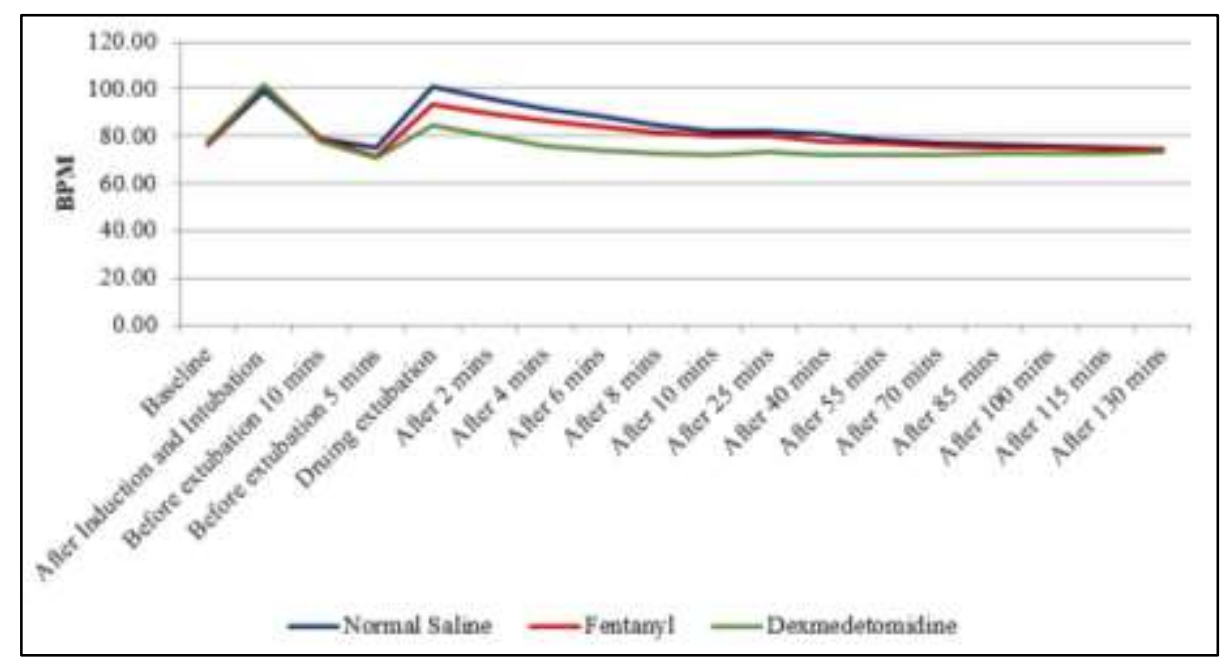

Fig. 1: Heart rate 


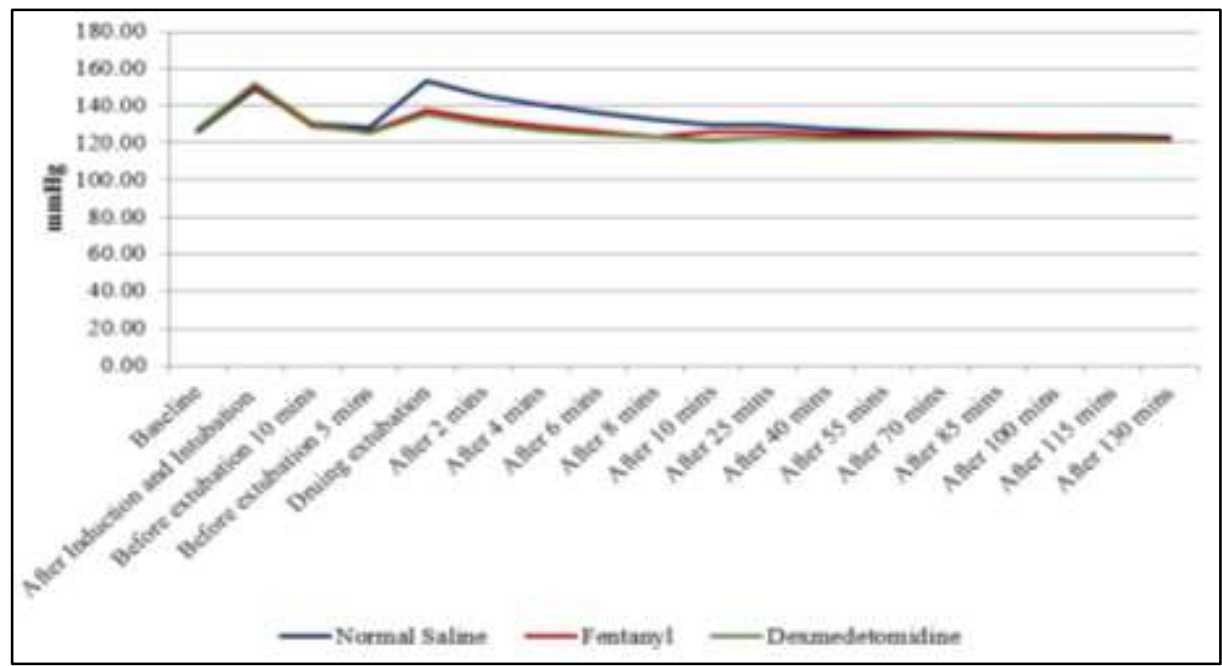

\section{Fig. 2: Systolic pressure}

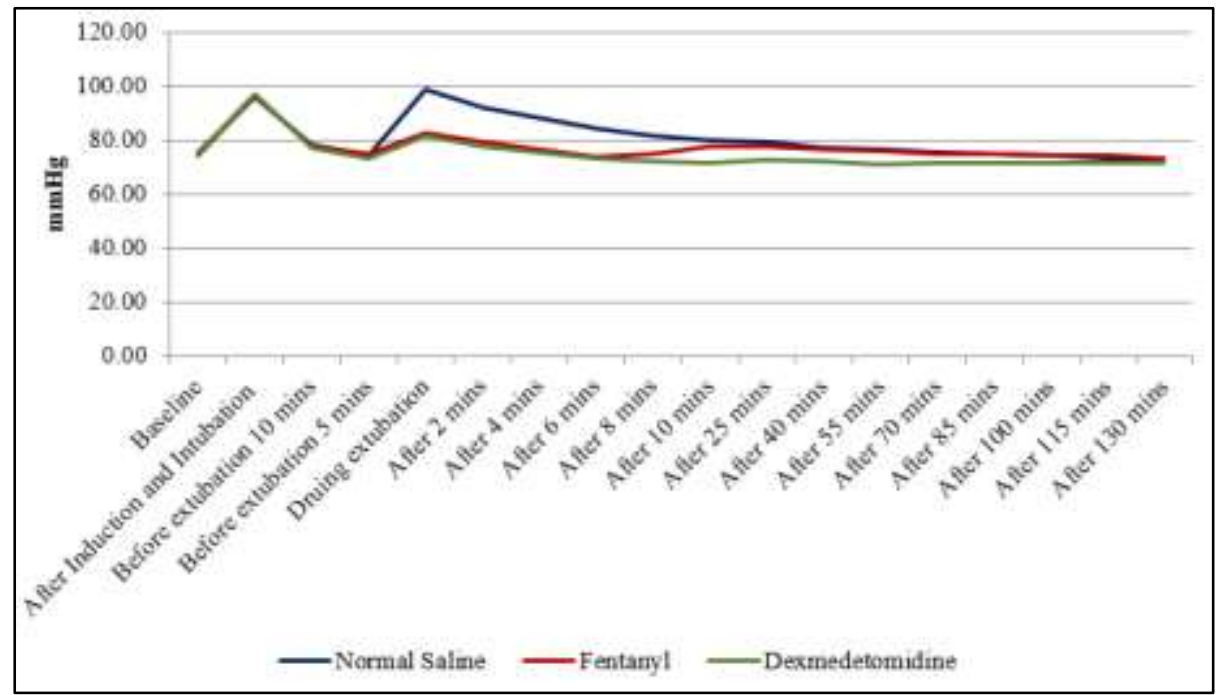

\section{Fig. 3: Diastolic pressure}

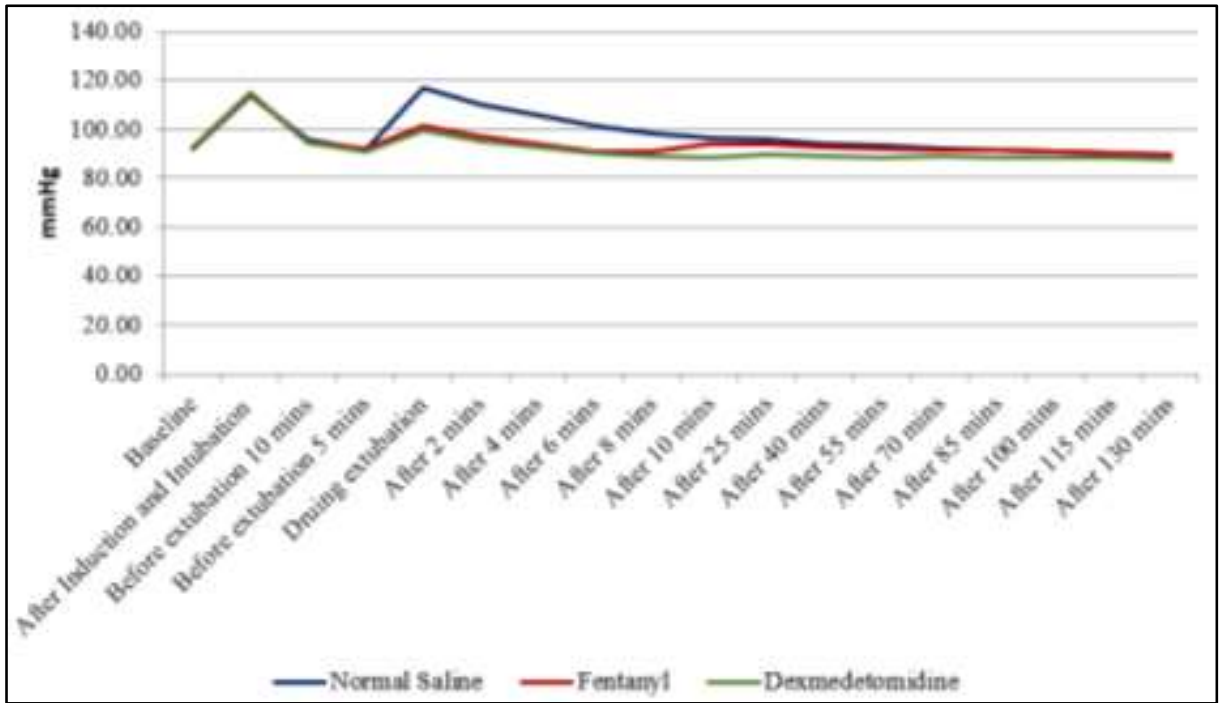

Fig. 4: Mean arterial pressure 
Table 1: Extubation quality score

\begin{tabular}{|c|c|c|c|c|c|}
\hline \multirow{2}{*}{ Group } & \multicolumn{4}{|c|}{ Extubation Quality Score } & \multirow{2}{*}{ P value } \\
\cline { 2 - 5 } & $\mathbf{1 . 0 0}$ & $\mathbf{2 . 0 0}$ & $\mathbf{3 . 0 0}$ & $\mathbf{4 . 0 0}$ & \\
\hline Normal Saline & 0 & 10 & 41 & 9 & \multirow{3}{*}{$<0.0001$} \\
\hline Fentanyl & 1 & 35 & 24 & 0 & \\
\hline Dexmedetomidine & 10 & 41 & 9 & 0 & \\
\hline Total & 11 & 86 & 74 & 9 & \\
\hline
\end{tabular}

Table 2: Ramsay sedation score

\begin{tabular}{|c|c|c|c|c|}
\hline \multirow{2}{*}{ Group } & \multicolumn{3}{|c|}{ Ramsay Sedation Score } & \multirow{2}{*}{ Total } \\
\cline { 2 - 4 } & $\mathbf{1 . 0 0}$ & $\mathbf{2 . 0 0}$ & $\mathbf{3 . 0 0}$ & \\
\hline Normal Saline & 5 & 54 & 1 & \multirow{2}{*}{0.199} \\
\hline Fentanyl & 3 & 54 & 3 & \\
\hline Dexmedetomidine & 0 & 57 & 3 & \\
\hline Total & 8 & 165 & 7 & \\
\hline
\end{tabular}

Table 3: Complications

\begin{tabular}{|c|c|c|c|c|}
\hline Complications & Normal Saline & Fentanyl & Dexmedetomidine & P value \\
\hline Bradycardia & 0 & 2 & 6 & 0.026 \\
\hline Hypotension & 0 & 0 & 2 & 0.132 \\
\hline Vomiting & 8 & 6 & 2 & 0.146 \\
\hline
\end{tabular}

\section{Discussion}

Endotracheal extubation is one of the frequently performed procedures in the field of anaesthesia. There is sympathetic stimulation which may cause detrimental effects in known hypertensive and coronary artery disease patients. Dexmedetomidine $0.5 \mu \mathrm{g} / \mathrm{kg}$ and fentanyl $1 \mu \mathrm{g} / \mathrm{kg}$ are the lowest possible doses studied for this purpose with significant effect. In the present study these two drugs were chosen to compare and find the better drug with the least adverse effects.

R.Aksu et al., compared intravenous dexmedetomidine $0.5 \mu \mathrm{g} / \mathrm{kg}$ with intravenous fentanyl $1 \mu \mathrm{g} / \mathrm{kg}$ given before extubation in 40 patients who underwent rhinoplasty. ${ }^{8}$ They found a statistically significant difference in the reduction of heart rate between the two groups starting from the time of extubation till the observations were made that is 10 minutes past extubation. In our study, dexmedetomidine usage was associated with lesser increase in heart rate compared with fentanyl. The decrease in heart rate between the dexmedetomidine and fentanyl groups were statistically significant from the time of extubation till the study length, that is 130 minutes after extubation. In a randomized, doubleblind, controlled study, Nishina et $\mathrm{al}^{3}$ compared the effects of fentanyl 1 and $2 \mu \mathrm{g} / \mathrm{kg}$ IV with those of a control group (placebo) on hemodynamic changes during tracheal extubation and emergence from anesthesia in 60 patients who underwent elective gynecologic surgery. Although those authors recommended the $2-\mu \mathrm{g} / \mathrm{kg}$ dose- because while the number of patients who experienced coughs or strains was similar among the 3 groups, the severity of these symptoms was attenuated in the fentanyl group that received the higher dose-they reported that the $1-$ and $2-\mu \mathrm{g} / \mathrm{kg}$ doses were associated with a significantly reduced HR $(\mathrm{P}<0.05)$ but found no significant difference in the prevalence of cough compared with placebo.
R. Aksu et al., found that the systolic blood pressure varies statistically significant between dexmedetomidine and fentanyl at 10 minutes after extubation. In a randomized, double-blind, placebo-controlled study, Guler et $\mathrm{al}^{9}$ reported that dexmedetomidine $0.5 \mu \mathrm{g} / \mathrm{kg}$ was associated with attenuation of both the prevalence and severity of airway and circulatory reflexes on emergence from anesthesia in intraocular surgery, without prolonged recovery. Cough scores were significantly lower in the dexmedetomidine group than in the placebo group $(\mathrm{P}<0.05)$, but there were no between-group differences in the prevalence of breath holding and desaturation. HR, SBP, and DBP were significantly increased from baseline at extubation in both groups $(\mathrm{P}<0.05)$, but the increase was significantly less substantial with dexmedetomidine. In our study dexmedetomidine group had statistically significant control of SBP than the fentanyl group during extubation and upto 70 minutes after extubation.

R. Aksu et al., observed that the diastolic blood pressure and mean arterial pressure varies statistically significant between dexmedetomidine and fentanyl at 10 minutes after extubation. In our study dexmedetomidine group showed a lesser rise in DBP and mean arterial pressure compared to fentanyl group from 5 minutes before extubation to 130 minutes after extubation which was statistically significant.

R. Aksu et al,. found that the fentanyl group had 25\%, $20 \%, 20 \%$ patients with minimal, moderate and severe cough respectively and 5\% had laryngospasm. Dexmedetomidine group $10 \%, 5 \%$ patients with minimal and moderate cough respectively. In our study, the fentanyl group had 58.3\%, 40\% patients had minimal and moderate cough respectively. In the dexmedetomidine group $68.3 \%, 15 \%$ patients had minimal and moderate cough respectively. More sample size in our study would have caused the difference. 
R. Aksu et al., found laryngospasm in $1(5 \%)$ patient in the fentanyl group. In our study, no patient had respiratory depression, laryngospasm, bronchospasm or desaturation in either groups. Aspiration of blood which is a risk of rhinoplasty surgeries might have caused the laryngospasm. In our study, hypotension was observed in $2(3.3 \%)$ patients in the dexmedetomidine group of which none required vasopressors.

R. Aksu et al., observed bradycardia in 4 patients ( 2 in each group) that is $10 \%$ patients in each group and these patients received atropine therapy when $\mathrm{HR}<45 / \mathrm{min}$. Nasocardiac reflex would have aggravated the bradycardia. In our study, bradycardia was observed in $2(3.3 \%)$ patients in the fentanyl group and 6(10\%) patients in the dexmedetomidine group which was statistically significant but clinically none of the patients required atropine.

Bajwa et al. observed a fall in oxygen saturation up to 94-95\% in the dexmedetomidine group, after the completion of dexmedetomidine infusion $(1 \mu \mathrm{g} / \mathrm{kg}$ in 20 minutes $) .{ }^{10} \mathrm{In}$ our study the least $\mathrm{SpO} 2$ recorded was $98 \%$. Yildiz et al observed significant sedation (with a short period of apnea in 3 cases) and a fall in $\mathrm{SpO} 2$ values immediately after drug infusion $1 \mu \mathrm{g} / \mathrm{kg}$ in 5 minutes. ${ }^{11}$ In our study lesser dose $(0.5$ $\mu \mathrm{g} / \mathrm{kg})$ in more time (10 minutes) decreased the incidence of apnea.

Liyakath et $\mathrm{al}^{6}$ compared dexmedetomidine $(1 \mu \mathrm{g} / \mathrm{kg})$ with fentanyl $(1 \mu \mathrm{g} / \mathrm{kg})$ with 150 patients divided into 3 groups of 50 each-normal saline, dexmedetomidine and fentanyl groups in normotensives undergoing elective surgeries. They found that the Ramsay sedation score during initial 25 minutes post-operatively among dexmedetomidine $(1 \mu \mathrm{g} / \mathrm{kg})$ group found to be higher than other 2 groups, fentanyl $(1 \mu \mathrm{g} / \mathrm{kg})$ and normal saline which was statistically significant. In our study, comparing the Ramsay sedation score during initial 25 minutes post-operatively among dexmedetomidine $(0.5 \mu \mathrm{g} / \mathrm{kg})$ group with the other groups, fentanyl $(1 \mu \mathrm{g} / \mathrm{kg})$ and normal saline produced a $\mathrm{P}$ value of 0.199 , which was statistically insignificant. Lawrence et al. administered a single preinduction IV dose of dexmedetomidine of $2 \mu \mathrm{g} / \mathrm{kg}$ (given over 5 minutes), and observed that most of the patients, who also received atropine premedication, were deeply sedated (Ramsay score 4-5) and had a higher incidence of hypotension and bradycardia. ${ }^{12}$ In our study lesser dose $(0.5 \mu \mathrm{g} / \mathrm{kg})$ decreased the sedative effect (Ramsay score 2-3).

\section{Conclusion}

Dexmedetomidine $0.5 \mu \mathrm{g} / \mathrm{kg}$ infusion administered 10 minutes before tracheal extubation was better compared to fentanyl $1 \mu \mathrm{g} / \mathrm{kg}$ infusion in attenuating the hemodynamic stress response with comparable adverse effects. Hence, dexmedetomidine infusion can be a safer alternative to fentanyl infusion for attenuating extubation stress response. Further studies can be done with a larger sample size and different doses of dexmedetomidine using neuromuscular block monitoring.

\section{References}

1. Minogue SC, Ralph J, Lampa MJ. Laryngotracheal topicalization with lidocaine before intubation decreases the incidence of coughing on emergence from general anesthesia. Anesth Analg 2004;99:1253-7.

2. Cranfield KA, Bromley LM. Minimum alveolar concentration of desflurane for tracheal extubation in deeply anaesthetized, unpremedicated children. Br J Anaesth 1997;78:370-1.

3. Nishina K, Mikawa K, Maekawa N, Obara H. Fentanyl attenuates cardiovascular responses to tracheal extubation. Acta Anaesthesiol Scand 1995;39(1):85-9.

4. Batra YK, Singh H, Singh SP. Blood pressure and Pulse rate changes during tracheal extubation, influence of topical or intravenous lidocaine. Indian J of Anaesth 1986;34:31-4.

5. Lam SW, Alexander E, Sulsa GM. DRUG UPDATE: Dexmedetomidine Use in Critical Care. AACN Adv Crit Care 2008;19:113-20.

6. Liyakhath Ali, Siddhram Jamgond, Jagadish M. B. Attenuation of Hemodynamic Stress Response During Emergence from General Anaesthesia: A Prospective Randomized Controlled Study Comparing Fentanyl and Dexmedetomidine. J Evol Med Dent Sci 2014;3(62):13686-96.

7. Antony D, Davies C.V, Thomas M.K, Shenoy U, Mahesh V, Puthumana K.J. The effect of two different doses of dexmedetomidine to attenuate cardiovascular and airway responses to tracheal extubation: a double blind randomized controlled trial. Int J Med Res Rev 2016;4(8):1392-403.

8. Aksu R, Akýn A, Bicer C, Esmaoglu A, Tosun Z, Boyacý A. Comparison of the effects of dexmedetomidine versus fentanyl on airway reflexes and hemodynamic responses to tracheal extubation during rhinoplasty: A double-blind, randomized, controlled study. Curr Ther Res Clin Exp 2009;70:209-20.

9. Guler G, Akin A, Tosun Z. Single-dose dexmedetomidine attenuates airway and circulatory reflexes during extubation. Acta Anesthesiol Scand 2005;49:1088-91.

10. Bajwa SS, Kaur J, Singh A, Parmar SS, Singh G, Kulshrestha A, et al. Attenuation of pressor response and dose sparing of opioids and anaesthetics with preoperative dexmedetomidine. Indian J Anaesth 2012;56:123-8.

11. Yildiz M, Tavlan A, Tuncer S, Reisli R, Yosunkaya A, Otelcioglu S. Effect of dexmedetomidine on haemodynamic responses to laryngoscopy and intubation: perioperative haemodynamics and anaesthetic requirements. Drugs $R D$ 2006;7:43-52.

12. Lawrence CJ, Lange SD. Effect of single pre-operative dexmedetomidine dose on isoflurane requirements and perioperative haemodynamic stability. Anaesth 1997;52:736-44.

How to cite this article: Amutharani R, Manoharan T,
Manickavasagam $\mathrm{P}$, Anandan H. Comparison of
intravenous dexmedetomidine and intravenous fentanyl to
attenuate the hemodynamic stress response to tracheal
extubation. Indian J Clin Anaesth 2019;6(2):242-7.

